\title{
Middlebrook 7H11S Growth Medium
}

National Cancer Institute

\section{Source}

National Cancer Institute. Middlebrook 7H11S Growth Medium. NCI Thesaurus. Code C127519.

A solid and selective growth medium modified from the Middlebrook 7H11 ag ar by the addition of four antimicrobial agents: polymyxin B, carbenicillin, amphotericin $B$, and trimethoprim lactate. 